\section{Australian Journal of \\ Crop Science}

AJCS 13(04):513-519 (2019)

doi: 10.21475/ajcs.19.13.04.p1345

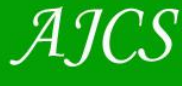

ISSN:1835-2707

\title{
Effect of calcium, BAP and putrescine on somatic embryo induction in juvenile explants of Eucalyptus grandis $\times E$. urophylla hybrids
}

\author{
Luciana Coelho de Moura ${ }^{1 *}$, Aloisio Xavier ${ }^{2}$, Ana Cláudia Ferreira da Cruz ${ }^{3}$, Diego Silva Batista ${ }^{3}$, Ricardo \\ Gallo $^{2}$, Natane Amaral Miranda ${ }^{2}$, Wagner Campos Otoni ${ }^{3}$
}

\author{
${ }^{1}$ Forest Engineering Department, Plant Tissue Laboratory, Federal University of Mato Grosso, Brazil \\ ${ }^{2}$ Forest Engineering Department, Plant Tissue Culture Laboratory/BIOAGRO, Federal University of Viçosa, Viçosa, \\ Brazil \\ ${ }^{3}$ Plant Biology Department, Plant Tissue Culture Laboratory/BIOAGRO, Federal University of Viçosa, Viçosa, Brazil
}

*Correspondence: lucianacm2005@yahoo.com.br

\begin{abstract}
Considering the constant improvement of Eucalyptus cloning and the search for new technologies to produce plantlets of this species, somatic embryogenesis has attracted interest from research groups and forestry companies that use advanced genetic breeding and cloning programs. The objective of the present study was to verify the effect of concentrations and sources of calcium, concentrations and effect time of cytokinin BAP and polyamine putrescine on the induction and development of somatic embryos in juvenile explants of Eucalyptus grandis $\times$ E. urophylla. Cotyledonary explants were inoculated into culture medium containing calcium chloride (MS medium) or calcium nitrate (JADS medium) as source of calcium. Different concentrations of calcium were also used, for MS medium containing: $4.40 \mathrm{gL}^{-1}$ (control-Ca), $6.60 \mathrm{gL}^{-1}$ (50\% increase over control - Ca 50) and $8.80 \mathrm{gL}^{-1}$ (increase of $100 \%$ over control - Ca 100) of calcium nitrate; and for JADS medium containing: $11.81 \mathrm{gL}^{-1}(\mathrm{Ca}), 17.72 \mathrm{gL}^{-1}(\mathrm{Ca} 50)$ and $23.62 \mathrm{gL}^{-1}$ (Ca100) of calcium chloride. Cotyledon explants were inoculated into the primary induction medium (PIM) containing $20.71 \mu \mathrm{M}$ picloram as growth regulator. At 10,20 and 30 days of primary induction, the explants were transferred to the secon dary induction medium (SIM) containing $20.71 \mu \mathrm{M}$ picloram and $11.10 \mu \mathrm{M}$ BAP or $28.36 \mu \mathrm{M}$ putrescine. The culture medium containing calcium nitrate provided higher callogenesis when compared to the medium containing calcium chloride. The increase in calcium concentration in the media did not provide higher percentage of induction of somatic pro-embryos. However, the addition of 28.36 $\mu \mathrm{M}$ putrescine to the culture medium provided a higher percentage of induction of somatic embryogenesis. The number of somatic pro-embryos formed per explant was higher when BAP and putrescine were added to the culture medium when compared to medium containing only picloram. To obtain a greater number of somatic pro-embryos of Eucalyptus grandis $\times E$. urophylla, the JADS culture medium containing $28.36 \mu \mathrm{M}$ putrecine should be used.
\end{abstract}

Keywords: In vitro propagation, JADS, micropropagation, polyamine, somatic embryogenesis.

Abbreviations: BAP_6-benzylaminopurine, BIOAGRO_Institute of Biotechnology Applied to Agriculture, Ca_control treatment of calcium, Ca50_50\% increase over control, Ca100_ increase of $100 \%$ over control, CAL_percentage of callogenesis, FC_percentage of friable callus formation, HC_percentage of callogenesis into high level, JADS_culture medium specific for Eucalyptus (Correia et al., 1995), LC_percentage of callogenesis into low level, MC_percentage of callogenesis into medium level, MS_culture medium (Murashige; Skoog, 1962), NAA_naphthaleneacetic, OXI_ percentage of oxidized explants, PIM_primary induction medium, PSE_percentage of somatic pro-embryos, PVP_polyvinylpyrrolidone, SIM_secondary induction medium, SPE_somatic pro-embryos formed per explant.

Introduction

Considering the constant improvement of Eucalyptus cloning and the search for new technologies to produce plantlets of this species, somatic embryogenesis has attracted interest from research groups and forestry companies that use advanced genetic breeding and cloning programs.

Several publications are found in the literature reporting propagation via somatic embryogenesis for some species of the genus Eucalyptus, such as Eucalyptus grandis (Major et al., 1997), Eucalyptus nitens (Bandyopadhyay et al., 1999; Bandyopadhyay and Hamill, 2000), Eucalyptus urophylla
(Arruda et al., 2000), Corymbia citriodora (Muralidharan and Mascarenhas, 1987; 1995) and Eucalyptus globulus (Bandyopadhyay et al., 1999). However, the application of this technique at commercial level is limited due to the lack of a complete, efficient and reproducible protocol, from the somatic embryo induction to the plantlet acclimatization. There are several factors, as well as complex interactions, that lead plant tissue cultures to become competent to neoformation programs and thus develop new organs or a whole new organism. As a main factor, are the high auxin 
levels, essential for the acquisition of the embryogenic competence (Fehér, 2015).

However, several other factors interfere during and in subsequent processes to induction, such as cytokinins, polyamines and calcium ions. In plants, cytokinins are required for the establishment of the bipolar structure in embryos, in addition to improving embryo development after somatic embryo induction (Ree and Guerra, 2015).

Polyamines have physiological regulatory functions during cell division (Ahmad et al., 2012), and have been studied as growth regulators in tissue culture as well as stress-reducing compounds in plants (Reis et al., 2016). The effect of polyamines, mainly putrescine, on somatic embryogenesis has been described for several species (Sakhanokho et al., 2005; Nieves et al., 2008; Wu et al., 2009; Silveira et al., 2013; Rajesh et al., 2014).

Calcium ions have the function of signal transduction to environmental stimuli and intracellular messengers in several processes of plant development (Poovaiah and Reddy, 1993; Bush, 1995; White and Broadley, 2003), among them, the embryonic development. Some authors suggest that increased levels of cytoplasmic calcium may be an important factor of embryogenic response in different species (Jansen et al., 1990; Etienne et al., 1997; Arruda et al., 2000; Malabadi and Standen, 2006; Ramakrsihna et al., 2011).

Given the above, the objective of this study was to verify the effect of concentration and source of calcium, and concentration and time of effect of BAP and putrescine on the induction and development of somatic embryos in juvenile explants of Eucalyptus grandis $x E$. urophylla.

\section{Results}

\section{Effect of calcium on the induction of somatic embryos}

Differences were found among the culture media for the total percentage of callogenesis and its levels (CAL, HC, MC and $\mathrm{LC}$ ) and for the percentage of friable callus formation (FC). The means in the medium containing calcium nitrate were superior for all these characteristics (PSE, CAL, HC, MC, $\mathrm{OXI}$ and SPE), except for the percentage of callogenesis at low level (LC), in which the medium containing calcium chloride was superior.

The mean values for the culture medium containing calcium nitrate were CAL: $92 \%, \mathrm{HC}: 24 \%$, MC: $54 \%$, LC: $13 \%$ and FC: $56 \%$ and for the culture medium containing calcium chloride were: CAL: $74 \%, \mathrm{HC}: 1 \%, \mathrm{MC}$ : $37 \%, \mathrm{LC}: 38 \%$ and FC: $24 \%$.

In relation to the calcium concentration, considering the two culture media studied, differences were found for the mean percentage of oxidation (OXI), percentage of total callogenesis (CAL), percentage of callogenesis at low level (LC) and percentage of friable callus formation (FC) (Fig 1). For the percentage of oxidized explants, the Ca concentration of the control was significantly higher than Ca50 (Fig 1A). In relation to the percentage of callogenesis, the mean of the control was higher than Ca100 for total callogenesis (CAL) and low callogenesis (CB) (Fig 1B). For the percentage of friable callus formation and somatic proembryos formed, the control was significantly higher than Ca100 (Fig 1C and 1D).

Somatic pro-embryos were induced indirectly, with the proliferation of disorganized cells (callus) preceding their formation.
In general, the induced PSE in Eucalyptus grandis $\mathrm{x} E$. urophylla stands out for their yellowish and shiny color (Fig $2 \mathrm{~A}$ and $\mathrm{B})$.

There was differentiation of the protoderm, characterized by cells arranged contiguous as well as the initial formation of the procambium. It is also observed the formation of a bipolar structure, characteristic of embryos, with regions of the shoot apical meristem (SAM) and root apical meristem (RAM) (Fig 2G).

In general, the number of somatic pro-embryos (SPE) was low: $1.0 ; 1.5$ and 1.2 for $\mathrm{Ca}, \mathrm{Ca} 50$ and $\mathrm{Ca} 100$, respectively, in the medium with calcium chloride; and 1.0; 0.8 and 1.4 for $\mathrm{Ca}, \mathrm{Ca} 50$ and $\mathrm{Ca} 100$, respectively, in the culture medium with calcium nitrate.

\section{Effect of BAP and putrescine on the induction of somatic embryos}

A significant interaction among the factors tested for the percentage of explant oxidation (OXI) was observed. At the 10-days interval between PIM and the SIM, the SIM with PUT resulted in more oxidized explants than SIM with BAP. At all the other time intervals between PIM and SIM, OXI in SIM did not differ statistically (Fig 3A). In the SIM with BAP, the 30-days interval between PIM and SIM showed more oxidized explants than the 10-day interval (Fig 3A).

There was a significant difference for high level callogenesis $\mathrm{HC}$ ) among the time intervals during the transition of PIM to SIM, with 30-day interval being higher than the 20-day (Fig 3B).

For the characteristic percentage of somatic pro-embryo formation (SPE), the SIM with PUT (mean 47\%) was more efficient in the induction of somatic embryogenesis than the SIM with BAP (mean 23\%) (Fig 3C).

As shown I the Fig 2, the SPE were formed indirectly and present a yellowish and bright color (Fig 2A and 2B). It is also observed the beginning of protoderm differentiation, characterized by the cells adjacently organized (Fig 2F). In general, embryo-forming cells have a high nucleus/cytoplasm ratio and smaller vacuoles, as can be seen in the similarities between Fig $2 \mathrm{E}$ and $2 \mathrm{~F}$, where the former corresponds to a zygotic embryo and the latter a somatic pro-embryo. There was also the formation of a phenolic cord delimiting the SPE, as well as the presence of phenolic compounds inside the cell (Fig 2C, 2D and 2F), which is characteristic in the preforming of somatic and zygotic embryos in some species. It is worth mentioning that the number of somatic embryos found in the second experiment was up to four times higher than those found in the first experiment, as can be observed in Fig 3D and comparing Fig 2A and 2B.

\section{Discussion}

The indirect somatic embryogenesis, characteristic of species of the genus Eucalyptus, is that one where there is formation of a disorganized mass of cells (callus) preceding the embryo formation. Thus, the callogenesis characteristics evaluated in this study are positive signs to further formation of somatic embryos, especially when there are friable callus. The friable callus is more suitable to initiate suspension culture cells when compared to compact callus, since the cells are disconnected from each other, without vascular elements and interspersed with intercellular spaces (Fransz and Schel, 1991). 

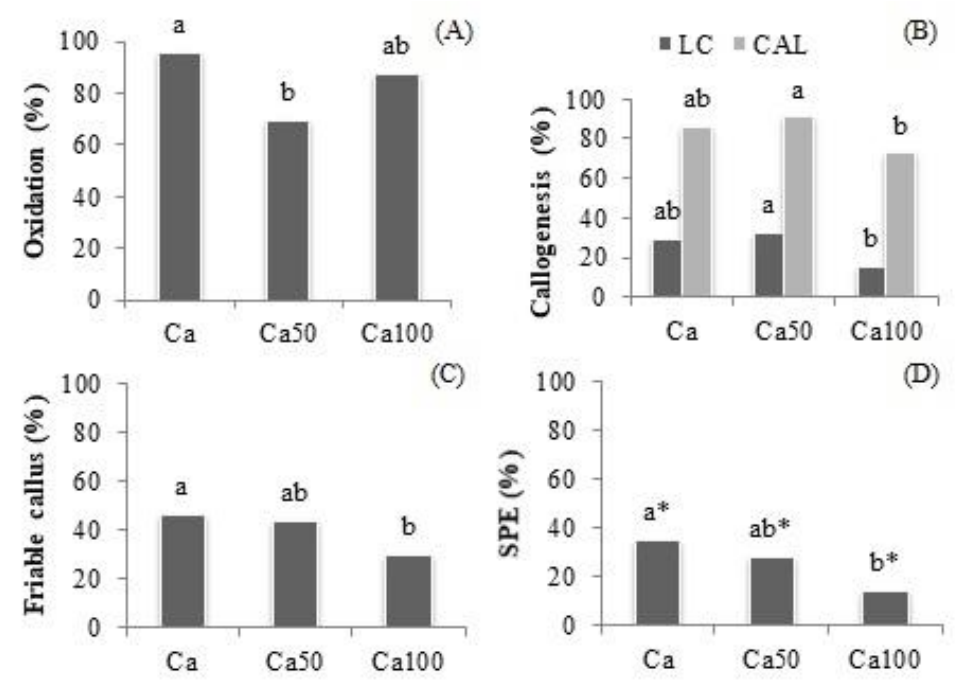

Fig 1. Percentage of oxidation (A); percentage of total callogenesis (CAL) and percentage of callogenesis at low level (LC) (B); percentage of friable callus (C); percentage of somatic pro-embryos (SPE) (D); in cotyledonary explants of Eucalyptus grandis $\mathrm{x} E$. urophylla submitted 40 days to different concentrations of calcium added to the culture medium [Ca - control; Ca50 (increase of $50 \%$ to the control) and Ca100 (increase of $100 \%$ to the control). Means followed with the same letter do not differ among themselves by the Tukey's test at 5\%. Letters with an asterisk were compared by the Tukey's test at 7\% probability.

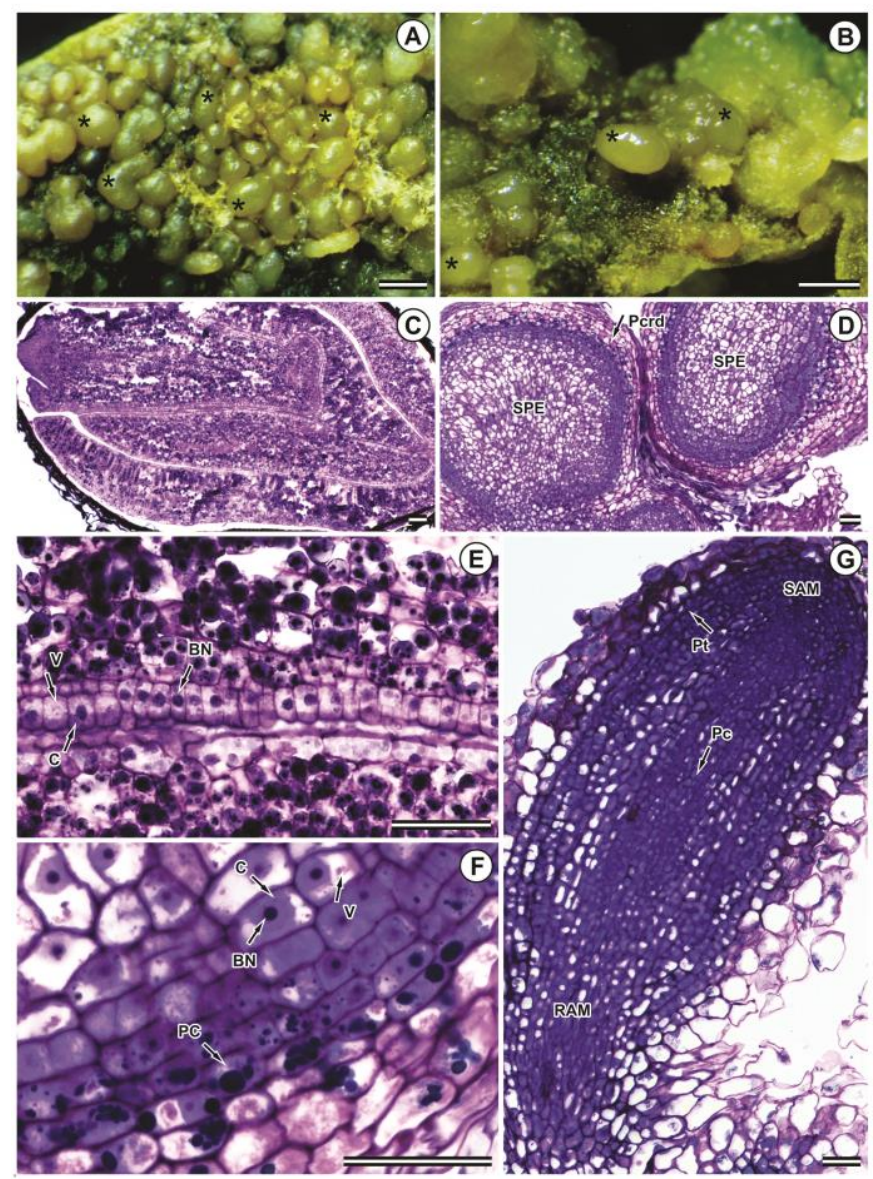

Fig 2. Embryogenic callus containing somatic pro-embryos (SPE) captured by stereoscopy (A and B) and longitudinal sections obtained by light microscopy (C, D, E, F and G) in Eucalyptus grandis x E. urophyllas. Zygotic embryo (seed) (C and E); somatic proembryo induced in culture medium containing calcium nitrate in Ca50 concentration (G); SPE induced in secondary induction medium (SIM) with putrescine during 30 days (B); SPE induced in SIM with BAP during 10 days (D and F) and 30 days (A). Bars in A and $B$ represent $1 \mathrm{~mm}$ and bars in $C, D, E, F$ and $G$ represent $50 \mu \mathrm{M} . C=$ cytoplasm; $P C r d=$ phenolic cord; $P C=$ phenolic compounds; $\mathrm{BN}=$ bulky nucleus; $\mathrm{Pc}=$ procambium; $\mathrm{Pt}=$ protoderm; $\mathrm{V}=$ vacuole; $\mathrm{RAM}=$ root apical meristem; $\mathrm{SAM}=$ shoot apical meristem; ${ }^{*}=$ Pro-somatic embryos. 

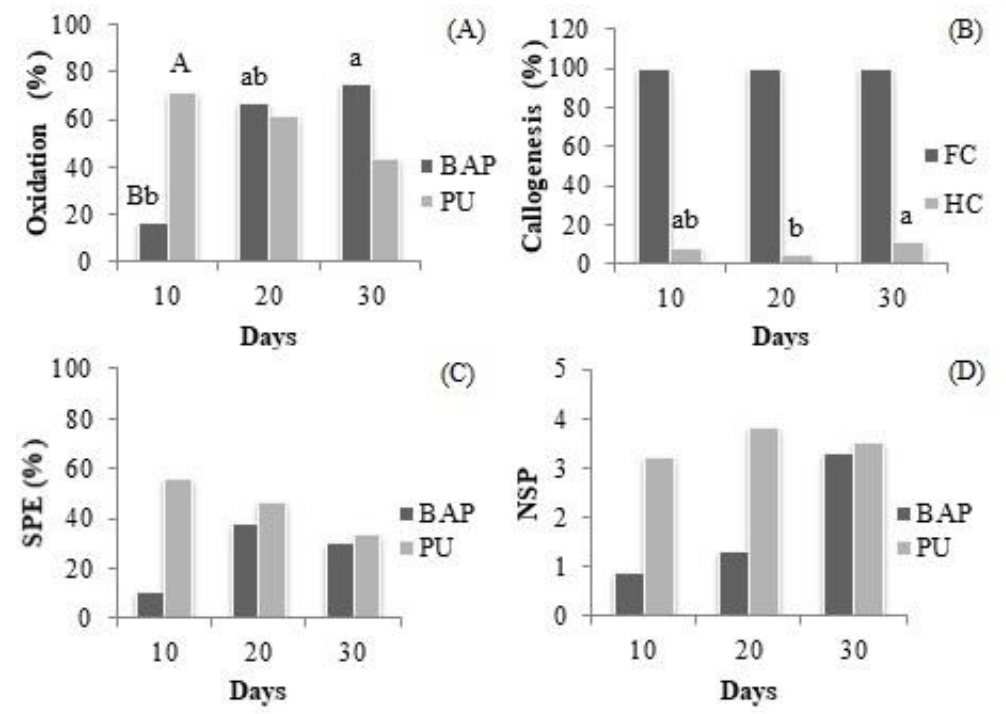

Fig 3. Percentage of oxidation (A); percentage of high level callogenesis (HC) and friable callus (FC) (B); percentage of somatic proembryos induction (SPE) (C); and number of somatic pro-embryos per explants (NSP) (D); in cotyledonary explants of Eucalyptus grandis $\mathrm{x}$. urophylla cultured 40 days with BAP or putrescine (PUT) and in different time intervals between the primary induction medium (PIM) and secondary induction medium (SIM). Means followed with the same uppercase letter do not differ between type of SIM (BAP or PUT) and means followed with the same lowercase letter do not differ among time intervals in PIM (10, 20 or 30), by the Tukey's test at $5 \%$.

High oxidation percentages of the explants were observed. Oxidation may occur when, in contact with the culture medium, the excised explants produces secondary metabolites resulting in a brownish color of the tissue. In some non-woody species, the callus oxidation causes absence of the embryogenic process until the explant death (Takamori et al., 2015). Whereas in woody species, such as Eucalyptus, the embryogenic callus oxidation is a process that precedes the embryo formation.

At histological and cellular level, the phenolic cord and phenolic compounds could be observed within the embryogenic callus cells in Eucalyptus grandis $x E$. urophylla. The oxidation of the tissues is usually seen in stress situations, which, at lower levels, cause changes in cell physiology and metabolism and induce mechanisms of adaptation such as cicatrization, organogenesis and somatic embryogenesis (Fehér, 2003).

Here we demonstrate that the interference of $\mathrm{Ca}$ concentrations on the callogenesis of the explants. An increase in calcium concentration, to a certain level, inhibits intercellular transport in plants through the block of plasmodesms (Tucker, 1990). This isolation of the initial cells is important to initiate friable callus and the embryogenic process (Williams and Maheswaran 1986). The calogens at all levels and the production of friable callus were higher when JADS medium was used, where the calcium source was calcium nitrate, in relation to MS medium, where the source of calcium was calcium chloride.

One of the major differences between these two culture media is the amount and the source of $\mathrm{Ca}$, with JADS medium having more than twice Ca than MS. Different sources of the same nutrient may present different responses in the same plant species, mainly due to the chemical formulation of the fertilizer, which influences its absorption and translocation in the plant. In addition, the other nutrients present in each of the calcium formulations used in the present study may influence the responses obtained. However, in the present study, the main responses obtained appear to be due to the higher calcium concentration in the JADS culture medium compared to MS. Experiments with calcium blockers and chelators inserted into sandal and carrot somatic embryogenesis induction medium indicated that the influx of exogenous calcium is essential for the start of somatic embryogenesis (Overvoode and Grimes, 1994; Anil and Rao, 2000; Anil et al., 2000). Higher Ca concentrations in the culture medium favored the maintenance of embryogenic potential and somatic embryos development in carrot cell cultures (Daucus carota) (Jansen et al., 1990), (Hevea brasiliesis) (Etienne et al. 1997), eucalyptus (Eucalyptus urophylla) (Arruda et al., 2000) and coffee (Coffea canephora) (Ramakrishna et al., 2011).

In Pinus, $\mathrm{Ca}$ ions work as a second messenger in the somatic embryogenesis signal transduction (Malabadi and Standen, 2006). Ca also participates in the onset of cell polarity during somatic embryogenesis (Overvoorde and Grimes, 1994; Timmers et al,. 1989, 1996). In studies with carrots, Timmers et al. (1996), showed the temporal and spatial variations of endogenous the $\mathrm{Ca}$. Ca concentrations varied according to the embryonic development stage, levels of auxins and cytokinins, and were concentrated in the nucleolus and in the somatic embryo protoderm (Timmers et al., 1996). These studies show how sensitive and variable is the concentration of Ca within embryogenic cells, with a need of more detailed studies about this element in the somatic embryogenesis of Eucalyptus.

As our results demonstrate, Putrescine (PUT) induced somatic pro-embryos in juvenile explant of Eucalyptus grandis $\mathrm{x} E$. urophylla. The percentage of somatic embryogenesis (SE) on the SIM containing PUT was twice than in the SIM containing BAP.

Although the endogenous cytokinins exert essential functions in the embryogenic process, its exogenous application promoted significant gains only in the amount of somatic pro-embryos per explant. An alternative to the 
addition of cytokinins in the ES induction medium is the inclusion of polyamines such as PUT, which can also be classified as a plant growth regulator.

Polyamines are small, low molecular weight, aliphatic molecules that have three amino-polycationic groups capable of interacting electrostatically with nucleic acid molecules, phospholipids, cell-wall compounds and proteins (Baron and Stolasol, 2008; Tiburcio et al., 2014).

The main polyamines in plants are putrescine, cadaverine, spermidine and spermine, usually associated with the regulation of physiological processes during cell division, protein synthesis, DNA replication and responses to abiotic stresses, acting in processes of organogenesis, embryogenesis, flowering, senescence and fruit maturation (Ahmad et al., 2012).

The behavior of polyamines seems to follow a similar pattern in some species, such as Vitis vinifera (Bertoldi et al., 2004), Coffea canephora (De-La-Pena et al., 2008), Pinus sylvestris (Vuosku et al., 2012) and Sacharum sp. (Silveira et al., 2013) during somatic embryogenesis induction, with the presence of a high concentration of PUT, followed by an intermediate spermidine and a lower spermine content. Reis et al. (2016) suggested that the role of PUT may be related to the modulation of peroxidases expression and other proteins responsible for supporting cells in oxidative stresses induced by excessive production of reactive oxygen species (ROS).

In Pinus, the addition of a PUT biosynthesis inhibitor in the culture medium inhibited the SE induction (Malabadi and Nataraja, 2007). In sugarcane, the incorporation of exogenous PUT resulted in a high content of intracellular free PUT, responsible for inducing better performance in the maturation of somatic embryos (Reis et al., 2016). In cotton, the inclusion of PUT promoted the germination and regeneration of plantlets produced via SE (Sakhanokho et al., 2005).

During the SE induction in plants, the most common way to induce the initial stress is the application of high auxin concentrations. There is an interaction of exogenous auxin with endogenous hormones, modification of gene expression and the induction of cellular dedifferentiation and re-differentiation in the embryogenic state (Jiménez, 2005). After the initial impulse to the embryogenic process, the exogenous application of other growth regulators may be essential, like the cytokinins, responsible for the axes formation and the establishment of the embryo bipolar meristem (Ree and Guerra, 2015), or polyamines, often associated with cell division and stress tolerance (KaurSawhney et al., 2003). Therefore, the objective of this study was to elucidate in which phase of somatic embryogenesis induction should be added other types of growth regulators. However, no significant differences were observed for the increase interval of PUT or BAP in the somatic embryogenesis induction medium.

Regarding to the number of SE produced per explant, both BAP and PUT treatments promoted higher pro-embryo production, when compared to the experiment in which only picloram was added. With the addition of PUT to the culture medium in sugarcane, the somatic embryo production almost tripled in relation to the control (Reis et al., 2016). This increase in the somatic embryo production can be due to the increase in cell division, a function regulated by both cytokinins and polyamines.

\section{Materials and methods}

\section{Plant material}

Hybrid mature seeds of Eucalyptus grandis $x E$. urophyll from APS 13 (Gerdau, Três Marias-MG), collected in January 2011, were used in that experiment. The hybrids are produced by controlled polinization in orchard of hydridation. Seedproducing trees are of reproductive age (between 7 and 10 years).

For disinfection, seeds were previously washed in tap water and immersed in $70 \%$ ethanol for 30 seconds and then in $5 \%$ sodium hypochlorite for 15 minutes, with $100 \mu \mathrm{L}$ of tween 20 for each $100 \mathrm{~mL}$ of solution. After this they were washed six times in autoclaved water and inoculated into sterile Petri dishes (90 x $15 \mathrm{~mm}$ ), containing half strenght MS basal salts solution (Murashige and Skoog, 1962), MS vitamin complex, $15 \mathrm{~g} \mathrm{~L}^{-1}$ of sucrose, $50 \mathrm{mg} \mathrm{L}^{-1}$ of myo-inositol, and $2.8 \mathrm{gL}^{-1}$ of Phytagel ${ }^{\oplus}$. The $\mathrm{pH}$ of the medium was adjusted to $5.8 \pm 0.1$, and the medium was autoclaved at $120^{\circ} \mathrm{C}$ and 1 atm. The plates were placed in growth room environment at $24 \pm 1{ }^{\circ} \mathrm{C}$, with light regime of $16 \mathrm{~h}$ and irradiance of $33 \mu \mathrm{mol}$ $\mathrm{m}^{-2} \mathrm{~s}^{-1}$, achieved by 2 fluorescent lamps ( $20 \mathrm{~W}, \mathrm{HO}$, Osram , Brazil) for 10 days.

\section{Effect of calcium on the induction of somatic embryos}

The cotyledons of the in vitro germinated plants were used as source of explants, which were inoculated into sterile Petri dishes $(60 \times 15 \mathrm{~mm})$ containing $15 \mathrm{~mL}$ of MS or JADS culture medium (Correia et al., 1995), with basal salts (except calcium) and vitamins, $30 \mathrm{~g} \mathrm{~L}^{-1}$ of sucrose, $100 \mathrm{mg} \mathrm{L}^{-1}$ of myo-inositol, and $7 \mathrm{gL}^{-1}$ of agar Merck , $20.71 \mu \mathrm{M} 4$ amino-3,5,6-trichloropicolinic acid (picloram) and different concentrations of calcium solution. In the MS medium the source of $\mathrm{Ca}$ was calcium chloride, at the concentration of $4.40 \mathrm{gL}^{-1}$, whereas in the JADS medium was $11.81 \mathrm{gL}^{-1}$ calcium nitrate. The treatments consisted of increasing the concentration of $\mathrm{Ca}$ in these two culture media, for $\mathrm{MS}$ medium: $4.40 \mathrm{gL}^{-1}$ (control-Ca), $6.60 \mathrm{gL}^{-1}$ (50\% increase over control - Ca 50) and $8.80 \mathrm{gL}^{-1}$ (increase of $100 \%$ over control - Ca100) of calcium nitrate; and for JADS medium $11.81 \mathrm{gL}^{-1}$ (Ca), $17.72 \mathrm{gL}^{-1}$ (Ca50) and $23.62 \mathrm{gL}^{-1}$ (Ca100) of calcium chloride. The $\mathrm{pH}$ was adjusted to $5.8 \pm 0.1$, and the medium was autoclaved at $120^{\circ} \mathrm{C}$ and $1 \mathrm{~atm}$. The plates were placed at the dark in growth room environment at $24 \pm 1^{\circ} \mathrm{C}$.

A completely randomized design was used, in factorial scheme $2 \times 3$ (types of culture medium $x$ concentrations of calcium solution), with 6 replicates and 10 explants/plate.

\section{Effect of BAP and putrescine on the induction of somatic embryos}

The cotyledons of the in vitro germinated plants were used as source of explants, which were inoculated into sterile Petri dishes $(60 \times 15 \mathrm{~mm}$ ) containing $15 \mathrm{~mL}$ of JADS medium with total basal salts and vitamins, $30 \mathrm{~g} \mathrm{~L}^{-1}$ of sucrose, 100 $\mathrm{mg} \mathrm{L}^{-1}$ of myo-inositol, and $7 \mathrm{gL}^{-1}$ of agar Merck. The $\mathrm{pH}$ of the was adjusted to $5.8 \pm 0.1$, and the medium was autoclaved at $120^{\circ} \mathrm{C}$ and $1 \mathrm{~atm}$. The plates were placed at the dark in growth room environment at $24 \pm 1{ }^{\circ} \mathrm{C}$.

The explants were kept in the dark at $24 \pm 1$ oC in the primary induction medium (PIM) with $20.71 \mu \mathrm{M}$ picloram as 
growth regulator. At 10, 20 and 30 days of primary induction, the explants were transferred to the secondary induction medium (SIM) containing $20.71 \mu \mathrm{M}$ picloram and $11.10 \mu \mathrm{M}$ 6-benzylamino purine (BAP) or $28.36 \mu \mathrm{M}$ 1, 4butanediamine (putrescine).

A completely randomized design was used, in factorial scheme $2 \times 3$ (types of SIM $x$ time of induction in PIM), with 10 replicates and 10 explants/plate.

\section{Variables analyzed and statistical analysis}

For both somatic embryo induction experiments the following evaluations were made at 40 days: percentage of somatic pro-embryos (PSE), percentage of callogenesis (CAL), which was divided into high (HC), medium (MC) or low (LC) levels, percentage of oxidized explants (OXI), percentage of friable callus formation ( $\mathrm{FC}$ ), and somatic pro-embryos formed per explant (SPE).

For all analyzes, the statistical software $R$, version 3.0.3 ( $R$ Core Team, 2014), and the ExpDes package (Ferreira el al., 2013) were used. The means were compared using Tukey's test.

\section{Anatomical characterization}

For the anatomical characterization, embryogenic calli were collected from all experiments at 40 days of induction. Samples were fixed in Karnovsky's solution (Karnovsky, 1965) for one week, dehydrated with serial increasing concentrations of ethanol and embedded in methacrylate resin (Historesin, Leica Instruments, Heidelberg, Germany). Cross and longitudinal sections with $5 \mathrm{~mm}$ thick were obtained with an automatic advance rotary microtome (RM2155, Leica Microsystems Inc., Deerfield, USA) and stained with toluidine blue ( $\mathrm{pH}$ 4.4) (O'Brien; McCully, 1981) for 10 minutes. Images were captured with an Olympus AX70TRF microscope (Olympus Optical, Tokyo, Japan) with a U-Photo Camera System (Spot Insight Color 3.2.0, Diagnostic Instruments Inc., USA).

\section{Conclusion}

In conclusion, it was observed in the present study that the culture medium with calcium nitrate provided greater callogenesis in cotyledonary explants of Eucalyptus grandis $\mathrm{x}$ $E$. urophylla, when compared to the medium containing calcium chloride. The increase in calcium concentrations did not provide higher induction of somatic pro-embryos. The addition of $28.36 \mu \mathrm{M}$ putrescine to the culture medium provided higher somatic embryogenesis induction in cotyledonary explants of Eucalyptus grandis x E. urophylla. The number of somatic pro-embryos formed per explant was higher when BAP and especially putrescine were added to the culture medium, when compared to medium with picloram.

\section{Acknowledgements}

The authors thank the Brazilian sponsoring agencies, CNPq (Conselho Nacional de Desenvolvimento Científico e Tecnológico, Brazil), FAPEMIG (Fundação de Amparo à Pesquisa do Estado de Minas Gerais), and CAPES (Coordenação de Aperfeiçoamento de Pessoal de Ensino
Superior), for financial support. We also acknowledge the BIOAGRO (Instituto de Biotecnologia Aplicada à Agropecuária) for provision of laboratory infrastructure.

\section{References}

Ahmad P, Kumar A, Gupta A, Hu X, Hakeem K R, Azooz M, Sharma $S$ (2012) Polyamines: role in plants under abiotic stress, in Ashraf M, Ozturk A, Msa A. Aksoy (Eds.). Crop Product Agricultura Improv. 491-512.

Anil VS, Harmon AC, Rao KS (2000) Spatio-temporal accumulation and activity of calcium-dependent protein kinases during embryogenesis, seed development and germination in sandalwood. Plant Physiol. 122: 1035-1041.

Anil VS, Rao KS (2000) Calcium-mediated signaling during sandalwood somatic embryogenesis: role for exogenous calcium as second messenger. Plant Physiol. 123: 1301-1311.

Arruda SCC, Souza GM, Almeida M, Gonçalves AN (2000) Anatomical and biochemical characterization of the calcium effect on Eucalyptus urophylla callus morphogenesis in vitro. Plant Cell Tiss Organ Cult 63: 145-154.

Bandyopadhyay S, Cane K, Rasmussen G, Hamill JD (1999) Efficient plant regeneration from seedling explants of two commercially important temperate eucalypt species Eucalyptus nitens and E. globulus. Plant Sci. 140: 189-198.

Bandyopadhyay S, Hamill JD (2000) Ultrastructural studies of somatic embryos of Eucalyptus nitens and comparisons with zygotic embryos found in mature seeds. Ann Bot. 86: 237-244.

Baron K, Stasolla C (2008) The role of polyamines during in vivo and in vitro development. In Vitro Cell Dev Biol Plant. 44: 384395.

Bertoldi D, Tassoni A, Martinelli L, Bagni N (2004) Polyamines and somatic embryogenesis in two Vitis vinifera cultivars. Physiol Plant. 120: 657-666.

Bush DS (1995) Calcium regulation in plant cells and its role in signalling. Annu Rev Plant Physiol Plant Mol Biol. 46: 95-122.

Correia D, Gonçalves AN, Couto HYZ, Ribeiro MC (1995) Efeito do meio de cultura líquido e sólido no crescimento e desenvolvimento de gemas de Eucalyptus grandis $\mathrm{x}$ Eucalyptus urophylla na multiplicação in vitro. Sientia Forestalis. 49/49: 107-116.

De-La-Pena C, Galaz-Avalos RM, Loyola-Vargas V (2008) Possible role of light and polyamines in the onset of somatic embryogenesis of Coffea canephora. Mol Biotechnol. 39: 215224.

Etienne H, Lartaud M, Carron MP, Michaux-Ferriere N (1997) Use of calcium to optimize long-term proliferation of friable embryogenic calluses and plant regeneration in Hevea brasiliensis (Mull. Arg.). J Exp Bot. 48: 129-137.

Fehér A (2015) Somatic embryogenesis - stress -induced remodeling of plant cell fate. Biochim Biophys Acta. 1849:385402.

Fehér A, Pasternak TP, Dudits D (2003) Transition of somatics plant cells to embryogenic state. Plant Cell Tiss Organ Cult. 74: 201-228.

Ferreira EB, Cavalcanti PP, Nogueira DA (2013) ExpDes: Experimental Designs pacakge. $\mathrm{R}$ package version 1.1.2.

Fransz PF, Schel JHN (1991) Cytodifferentiation during the development of friable embryogenic callus of maize (Zea mays). Can J Bot. 69 (1): 26-33.

Jansen MAK, Booij H, Schel JHN, De Vries SC (1990) Calcium increases the yield of somatic embryos in carrot embryogenic suspension cultures. Plant Cell Rep. 9: 221-223.

Jiménez VM (2005) Involvement of plant hormones and plant growth regulators on in vitro somatic embryogenesis. Plant Growth Regul. 47: 91-110. 
Karnovsky MJ (1965) A formaldehyde-glutaraldehyde fixative of high osmolality for use in electron microscopy. J Cell Biol. 27: 137-138.

Kaur-Sawhney R, Tiburcio AF, Altabella T, Galston AW (2003) Polyamines in plants: an overview. J Cell Mol Biol. 2: 1-12.

Major G, Krause M, Ross S, Sotelo, M (1997) Preliminary studies on the somatic embryogenesis in Eucalyptus grandis. In: IUFRO Conference on Silviculture and Improvement of Eucalyptus, Salvador. Proceedings... Colombo: Embrapa 1:137-142.

Malabadi RB, Natajara K (2007) Putrescine influences somatic embryogenesis and plant regeneration in Pinus gerardiana Wall. American J Plant Physiol. 2 (2): 107-114.

Malabadi RB, Van Staden J (2006) Cold-enhanced somatic embryogenesis in Pinus patula is mediated by calcium. S Afr J Bot. 72: 613-618.

Murashige T, Skoog F (1962) A revised medium for rapid growth and bioassays with tobacco tissue cultures. Physiol Plant. 15: 473-497.

Muralidharan EM, Mascarenhas AF (1987) In vitro plantlet formation by organogenesis in Eucalyptus camaldulensis and by somatic embryogenesis in E. citriodora. Plant Cell Rep. 6: 256-259.

Muralidharan EM, Mascarenhas AF (1995) Somatic embryogenesis in Eucalyptus. In: Jains SM, Gupta PK, Newtons RJ. (Ed.). Somatic embryogenesis in Woody plants. Kluwer Academic Publishers 2: 23-40.

Nieves N, Sagarra F, Gonzalez R, Lezcano Y, Cid M, Blanco MA, Castilo R (2008) Effect of exogenous arginine on sugarcane (Saccharum sp.) somatic embryogenesis, free polyamines and the contents of the soluble proteins and proline. Plant Cell Tiss Organ Cult. 95: 313-320.

O'Brien TP, McCully ME (1981) The study of plant structure: principles and selected methods. Termarcarphi OPTY. LTD: Melbourne.

Overvoorde PJ, Grimes HD (1994) The role of calcium and calmodulin in carrot somatic embryogenesis. Plant Cell Physiol. 35: 135-144.

Poovaiah BW, Reddy ASN (1993) Calcium and signal transduction in plants. CRC Crit Rev Plant Sci. 12: 185-211.

R Core Team (2014) MR: A language and environment for statistical computing. R Foundation for Statistical Computing, Vienna, Austria. Available in: http://www.Rproject.org/

Rajesh MK, Radha E, Sajini KK, Karun A (2014) Polyamineinduced somatic embryogenesis and plantlet regeneration in vitro from plumular explants of dwarf cultivars of coconut (Cocos nucifera) Indian J Agricult Sci./Short communication 84 (4): 527-30.

Ramakrishna A, Giridhar P, Ravishankar GA (2011) Calcium and calcium ionophore A23187 induce high-frequency somatic embryogenesis in cultured tissues of Coffea canephora P ex Fr. In Vitro Cell Dev Biol Plant. 47(6): 667-673.

Ree JF, Guerra MP (2015) Palm (Arecaceae) somatic embryogenesis. In Vitro Cell Dev Biol Plant. 51: 589-602.

Reis RS, Vale EM, Heringer AS, Santa-Catarina C, Silveira V (2016) Putrescine induces somatic embryo development and proteomic changes in embryogenic callus of sugarcane. J Proteomics 130: 170-179.
Sakhanokho HF, Ozias-Akins P, May OL, Chee PW (2005) Putrescine enhances somatic embryogenesis and plant regeneration in upland cotton. Plant Cell Tiss Organ Cult. 81: 91-95.

Silveira V, Vita AM, Macedo AF, Dias MRF, Floh EIS, SantaCatarina C (2013) Morphological and polyamine content changes in embryogenic and non-embryogenic callus of sugarcane. Plant Cell Tiss Organ Cult. 114: 351-364.

Takamori LM, Neto NBM, Vieira LGE, Ribas AF (2015) Optimization of somatic embryogenesis and in vitro plant regeneration of Urochloa species using picloram. In Vitro Cell Dev Biol Plant. 51: 554-563.

Tiburcio A, Altabella T, Bitrián M, Alcázar R (2014) The roles of polyamines during the lifespan of plants: from development to stress. Planta 240: 1-18.

Timmers ACJ, De Vries SC, Schel JHN (1989) Distribution of membrane-bound calcium and activated calmodulin during somatic embryogenesis of carrot (Daucus carota L.). Protoplasma 153: 24-29.

Timmers ACJ, Reiss H-D, Bohsung J, Traxel K, Schel JHN (1996) Localization of calcium during somatic embryogenesis of carrot (Daucus carota L.). Protoplama 190: 107-118.

Tucker EB (1990) Calcium-loaded 12-bis (2-aminophenoxy) ethane- N NN ' $N$ ' -tetraacetl.c acid. block.s cell-.to-cel dtffuslon of carboxy fluorescein in staminal hairs of Setcreasea purpurea. Planta 182:34-38.

Vuosku J, Suorsa M, Ruottinen M, Sutela S, Muilu-Makela R, Julkunen-Tiitto R, Sarjala T, Neubauer P, Hãggman H (2012) Polyamine metabolism during exponential growth transition in Scots pine embryogenic cell culture. Tree Physiol. 32: 12741287.

White PJ, Broadley MR (2003) Calcium in plants. Ann Bot. 92 (4) 487-511.

Williams EG, Maheswaran G (1986) Somatic embryogenesis: factors influencing coordinated behaviour of cells as an embryogenic group. Ann Bot. 57: 443-462.

Wu XB, Wang J, Liu JH, Deng XX (2009) Involvement of polyamine biosynthesis in somatic embryogenesis of Valencia sweet orange (Citrus sinensis) induced by glycerol. J Plant Physiol. 166: 52-62. 